\title{
HUGO DOS REIS E A SOCIEDADE PONTA- GROSSENSE: A ATUAÇÃO DO JORNALISTA NO DIÁRIO DOS CAMPOS
}

\author{
HUGO DOS REIS AND THE SOCIETY OF PONTA \\ GROSSA: THE WORK OF THE JOURNALIST AT DIÁRIO \\ DOS CAMPOS
}

Isaias Holowate ${ }^{l}$

\section{Resumo:}

O presente artigo faz um estudo da atuação do jornalista Hugo dos Reis na sociedade ponta-grossense entre os anos de 1908 e 1921. Tendo vindo do Rio de Janeiro em 1908, ele atuou em Ponta Grossa junto ao jornal local O Progresso - depois Diário dos Campos -, em diversas funções, sendo redator, diretor e posteriormente, proprietário do jornal. No periódico, promoveu o surgimento de uma classe de colaboradores da publicação, permitindo a presença de uma diversidade de representações sobre a sociedade daquele período. Na pesquisa utiliza-se como fonte, as publicações dos jornais O Progresso e Diário dos Campos e entre 1908 e 1921 e embasados pela teoria das Representações do historiador Roger Chartier, analisa-se os sentidos produzidos pelo jornalista sobre o meio social ao qual fez parte, compreendendo que as representações são socialmente construídas e se relacionam com o ambiente social e cultural em que seus signos são produzidos.

Palavras-chave: Representações; Relações sociais; Diário dos Campos.

\footnotetext{
${ }^{1}$ Graduando em História pela Universidade Estadual de Ponta Grossa
} 


\section{Abstract:}

The following article observes the work of the journalist Hugo dos Reis in the society of the city of Ponta Grossa on the years between $1908 \mathrm{e}$ 1921. Coming from Rio de Janeiro in 1908, he worked on the local paper $O$ Progresso - and after that in the Diário dos Campos - in various assignments, being a drafter, director and soon after, owner of the newspaper. He was responsible for bringing up a new class of collaborators to the publication, allowing for a diversity of representations about the society of that time period. In this research we use the publications of the newspaper $O$ Progresso e Diário dos Campos that were created in the time period between 1908 and 1921 as sources and we base our conjectures on the Theory of Representations of the historian Roger Chartier by analyzing his impressions about the social ambient where he was inserted, understanding that those representations are social constructs and relate to the social and cultural ambient where their signs are reproduced.

Keywords: Representations; Social Relations; Diário dos Campos.

\section{Introdução:}

No ano de 1908, o jornalista carioca Hugo Mendes de Borja Reis chegou a cidade de Ponta Grossa, no Paraná. Tendo fixado residência, ele que já tinha experiência com o jornalismo no Rio de Janeiro, tratou de ligar-se ao periódico local O Progresso - que depois se chamaria Diário dos Campos - onde atuou entre os anos de 1908 e 1921, participando da equipe editorial do jornal.

Sua atuação junto a imprensa ponta-grossense é um dos principais responsáveis pela presença, no jornal, de uma diversidade de representações sobre a sociedade daquele período. O jornalista possuía uma formação cultural que em diversos aspectos se diferenciava dos 
princípios habitualmente defendidos pelos grupos locais e particularmente, a burguesia letrada urbana ao qual o jornalista buscou se inserir.

$\mathrm{Na}$ sua participação no jornal, ele teve ocasião de afirmar seus preceitos, questionar princípios aos quais não concordava e ser inquirido e acusado sobre seus posicionamentos, em virtude das suas convicções políticas, sociais e religiosas. Defensor do espiritualismo científico ${ }^{2}$, Reis foi também um combatente em favor das causas sociais e se posicionou defendendo bandeiras relativas à melhoria da educação (REIS, 9 Out. 1915: 1) e da saúde (REIS, 27 mar. 1918: 1).

Uma das características da participação de Hugo dos Reis na sociedade ponta-grossense, foi o seu reconhecimento no meio jornalístico local. Numa época de fortalecimento das profissões liberais, a sua recognição no meio jornalístico ponta-grossense foi possível graças a aceitação da sociedade local e do grupo ao qual ele se inseriu, que aceitou-o como membro (HOLOWATE, 2015b). O historiador Roger Chartier, ao defender que as relações sociais são determinantes para construção das representações sobre a atuação do indivíduo, aponta que: "A realidade de uma posição social não é mais do que aquilo que a opinião

${ }^{2}$ Espiritualismo científico é a uma corrente ideológica que atingiu boa parte da intelectualidade brasileira no final do século XIX e início do século XX. Partindo do movimento Kardecista, teve notoriedade na segunda metade do século XIX, após a morte de Allan Kardec, e a primeira metade do século XX. Seus propagadores associavam o discursos espiritualista com científico e que deveria ser compreendida no sentido estrito da palavra. Segundo Maldonado (2008: 11) "boa parte da intelectualidade brasileira do século XIX interessou-se pela doutrina espírita e até mesmo converteu-se a ela". 
considera que ela é: É o reconhecinento, pelos outros, da qualidade de membro dessa sociedade que, em ultima análise, decide sobre essa mesma qualidade" (CHARTIER, 1990: 112).

Na pesquisa, a fonte ${ }^{3}$ utilizada consiste de publicações da imprensa ponta-grossense, do jornal O Progresso entre 1908 e 1912, e do seu sucessor, o jornal Diário dos Campos, entre os anos de 1913 e 1921, na época em que o Hugo dos Reis fez parte do corpo editorial da publicação. A utilização de fontes jornalísticas em pesquisas históricas, tem se tornado mais comum nas ultimas décadas, principalmente após a diversificação das fontes e métodos de pesquisa promovidos pela terceira geração da Escola dos Annales (LE GOFF e NORA, 1978: 11-12).

Luca (2011: 111-153) aponta para os avanços na pesquisa em jornais, que se tornaram uma importante fonte de pesquisa para diversas áreas. Os documentos jornalísticos contém uma diversidade de representações sobre seu tempo e apresentam uma variedade de possibilidades de pesquisa, pois, tais documentos, além de serem uma ferramenta comunicativa, trazem consigo os usos sociais da notícia e revelam interesses aos quais essas publicações defendem. Estudar o jornal pode possibilitar uma melhor compreensão das formas com que indivíduos pertencentes a determinados grupos, pensam, praticam e representam a sua realidade.

\footnotetext{
${ }^{3}$ Nas citações de fontes, optou-se por realizar a transcrição literal das fontes, de forma a manter a fidelidade da grafia e a historicidade dos termos do período estudado.
} 
A pesquisa em periódico envolve o reconhecimento da fonte como uma ferramenta que constrói uma realidade. Ao mesmo tempo, as representações construídas nas páginas dos periódicos são influenciadas pelo meio social ao qual fazem parte, realizando uma constante troca de informações. O jornal, ao mesmo tempo em que influencia a opinião de seus leitores, também sofre influência dos grupos que acessam à publicação, sejam eles os patrocinadores, produtores, colaboradores ou consumidores (PONTES e SILVA, 2012: 52).

$\mathrm{Na}$ análise de representações em jornais, também é importante atentar para a historicidade da fonte e das representações nela contidas. Por isso, faz-se importante que esses documentos sejam submetidos ao crivo de uma pesquisa que envolva a utilização de um método. Sobre os aspectos metodológicos de pesquisa nos jornais, Luca (2011: 140) afirma que:

O pesquisador dos jornais e revistas trabalha com o que se tornou notícia, que por si só já abarca um espectro de questões, pois será preciso dar conta das motivações que levaram à decisão de dar publicidade a alguma coisa. [...] Em síntese, os discursos adquirem significados de muitas formas. [...] A ênfase em certos temas, a linguagem e a natureza do conteúdo tampouco se dissociam do público que o jornal ou a revista pretende atingir.

Por isso, compreende-se que as publicações de um jornal não apresentam a "verdade por si só"; são documentos socialmente construídos e dizem respeito à cultura na qual foram produzidas. Portanto, no 
estudo das representações nos jornais deve-se entender que as publicações presentes em uma edição são ressignificações da realidade.

Para os estudos dessas ressignificações toma-se por pressuposto os princípios da Teoria das Representações, defendido pelo historiador Roger Chartier, que compreende a relação da realidade/representação através da relação signo - significado "entendida, deste modo, como relacionamento de uma imagem presente e de um objecto ausente, valendo aquela por este, por Ihe estar conforme" (CHARTIER,1991:184). Na representação "o real assume [...] um novo sentido: aquilo que é real, efetivamente, não é”, (CHARTIER, 1990: 62) e deixando para trás a dualidade verdade/ficção, a História das Representações busca compreender as representações da realidade produzida pelo indivíduo.

Por ser o jornal um documento histórico, a análise das representações busca compreender os fatores que determinaram os discursos do periódico, e suas especificidades, desde seu formato, abrangência, apresentação, paginação, sua estrutura das matérias, colaborações, hierarquias discursivas e debativas, além de analisar o contexto e texto em que tais matérias forma produzidas.

Portanto, para a compreensão das representações produzidas por Reis sobre o seu tempo, faz-se necessário entender o contexto social do qual ele fazia parte, investigar a estrutura do jornal nesse período, a estruturação e as transformações na sociedade em que ele veio a residir, e no estudo da construção de sentidos do jornalista sobre a sociedade local, compreender nas publicações do jornalista e seus colegas de peri- 
ódico, as relações estabelecidas no âmbito do jornal e as representações produzidas sobre a sociedade em que ele vivia.

\section{A sociedade ponta-grossense do início do século XX}

A sociedade ponta-grossense em que Hugo dos reis se inseriu, havia passado por um período de uma crise na economia rural na segunda metade do século XIX, o que deu origem a uma diversificação da economia, que passou a ser estruturada nas recém-criadas indústrias como a madeireira (KOHLRAUSCH, 2007: 20) e a ervateira (LEANDRO, 1995: 12).

As transformações econômicas ocorreram contiguamente ao fenômeno de urbanização da cidade, provocando uma modificação estrutural na sociedade. No final do século XIX, a região passou por um período de intensa imigração que trouxe pessoas de diversas nacionalidades, possibilitando a existência de uma sociedade caracterizada por uma multiplicidade cultural. A população ponta-grossense passou entre o final do século XIX e o início do século XX, de 4774 habitantes de acordo com o Censo de 1890, para 20771 no Censo de 1920 (PINTO, 1980: 61).

Nesse período se estabeleceu uma distinção mais clara entre o rural e o urbano (PEREIRA, 1996: 97-115), criando-se um sentimento de identidade urbana. A atuação na cidade, associado cada vez mais à 
riqueza e ao progresso, acentua e diferencia o meio rural da urbanidade ponta-grossense. Tal como afirma Zulian (1998: 40):

Transformações sensiveis na estrutura social e econômica vão se evidenciando na Ponta Grossa do fim do século, que se manifestam na concentração urbana e em contraste com a dispersão rural de proprietários em busca de outro tipo de atividade. Em função destas transformações, Ponta Grossa, que parecia confundir-se com o campo que a invadia, assume "ares de cidade".

O fenômeno da urbanização também modifica o imaginário da cidade. Anteriormente, as cidades dos Campos Gerais ${ }^{4}$, além de serem pequenas e quase indistintas da área rural, se caracterizavam por uma dependência em relação à economia das fazendas e do tropeirismo, ambas as atividades principalmente rurais. Contudo, a partir do final do século XIX, com a urbanização e industrialização, a população campestre orbita a cidade, que passa agora a ser um local de atração. A cidade é o lugar do progresso, por excelência. Lá se discutia politica e sociedade, se comercializava matérias-primas e produtos industrializados, e uma parcela da população se divertia nos lugares morigerados ${ }^{5}$ ou não. Estar

\footnotetext{
${ }^{4}$ A região dos Campos Gerais no Paraná ocupa uma faixa de território do Segundo Planalto paranaense, entre o Planalto Curitibano e o Planalto de Guarapuava. Caracteriza-se por ser uma região campeira, que durante os séculos XVIII e XIX, foi ocupada pela economia tropeira, com a instalação das fazendas de engorda dos animais que passavam pela região.

${ }^{5} \mathrm{O}$ termo "morigerado" era frequentemente utilizado na sociedade paranaense do século XIX para referir-se aos indivíduos cujas qualidades eram defendidas pelas elites socieconômicas. $\mathrm{O}$ indivíduo morigerado era aquele que defendia $\mathrm{o}$
} 
na cidade era um símbolo de status superior para os grupos modernizantes da população.

Nessa época, muitos dos filhos de fazendeiros partiam em direção às capitais de São Paulo, Rio de Janeiro e Pernambuco, onde realizavam seus cursos de bacharéis, e após retornarem à região, assumiam postos de empregos públicos e cargos na política ponta-grossense (LEANDRO, 1995: 13).

Nesse mesmo período, os códigos de postura buscam regrar as práticas sociais da população, através da ordenação dos espaços urbanos e a busca pelo estabelecimento de normas de controle das ações dos indivíduos (PEREIRA, 1996: 6). Ao mesmo tempo, a ordenação da população procurava criar uma identidade cultural de classe média em torno dos discursos progressistas doutrinadores daquele momento, como a ideologia de ciência que se tornava cada vez mais poderosa.

A noção de civilização se afirmaria, principalmente, no caráter desse progresso. É um progresso, em seus diversos aspectos, à moda européia. A cidade vai surgindo como uma urbe cosmopolita, onde o comércio, a estrada de ferro, o novo arruamento, as construções, os habitantes (sérios, ordeiros, empreendedores) e seus novos hábitos civilizados são elementos denotativos de uma "nova Ponta Grossa" ( ZULIAN, 1998: 53).

trabalho, a acumulação de capital, comportando-se de acordo com as leis e regras de etiqueta sociais. Os não-morigerados eram aqueles que constrariavam essas regras e constituíam a grande maioria da população. (PEREIRA, 1996: 5) 
Essa nova burguesia contava com muitos personagens que defendiam os ideais positivistas. O progresso é associado à ocupação do interior e ao desenvolvimento tecnológico da região. Assim como a chegada da ferrovia, a criação do periódico O Progresso - que viria a ser o Diário dos Campos - representam, nesse momento, como aponta Chaves (2011: 30-31), algo que tendia a ser percebido por alguns grupos da sociedade local, como um importante avanço da cidade rumo a sua modernização.

O aumento populacional significou também um aumento de necessidades de estruturas políticas e sociais capazes de atender às recentes demandas da população. Segundo os colaboradores do Diário dos Campos, a estrutura municipal não tinha condições de arcar com o preço da urbanização, e as transformações na estrutura urbana não acompanharam as mudanças sociais, acentuando os problemas no ambiente citadino e tornando as condições de vida difíceis para a maioria da população mais pobre.

Portanto, a cidade de Ponta Grossa se urbanizou sem haver propriamente uma preocupação das autoridades com a massa que imigrava para a região. Os constantes apelos dos colaboradores do jornal para o risco de uma degeneração racial citam a falta de estrutura sanitária, cultural e social para atender à população. Com o crescimento populacional houve um inchamento da cidade, provocando a multiplicação das tensões sociais. As publicações do Diário dos Campos denunciam constantemente a intensificação da criminalidade na área urbana, e supostos 
"males" como o "jogo", a "prostituição", o "alcoolismo" e a "vagabundagem". Com uma estrutura sanitária escassa, a cidade era também vítima constante de epidemias de tifo, sífilis e febre amarela. As páginas do jornal constantemente reclamam ações das autoridades em relação aos problemas da cidade em expansão.

\section{A personalidade de Hugo dos Reis no Diário dos Campos}

O discurso jornalistico do Diário dos Campos, no início do século XX, esteve sempre atrelado às ideologias de ciência e progresso. Ambas estiveram presentes no cenário nacional desde o movimento de Proclamação da República, sendo que $O$ Progresso foi o nome utilizado inicialmente pelo jornal publicado pela primeira vez em 27 de abril de 1907 (DIÁRIO DOS CAMPOS, 27 abr. 1922: 1) em Ponta Grossa, com uma tiragem de 300 exemplares.

O jornal foi criado por Jacob Holzmann, um imigrante russoalemão que chegou à cidade no final do século XIX, e que teve uma grande importância na política ponta-grossense. Holzmann foi membro de uma burguesia atuante na cidade, um dos fundadores da Companhia Tipográfica pontagrossense e personagem influente das discussões políticas locais, tendo sido considerado por José Cadilhe como o "Fundador da Imprensa de Ponta Grossa" (CHAVES, 2011: 29). O jornal inicialmente publicado quinzenalmente, após poucas edições, passou a ser publicado a cada três dias. 
A publicação consistia, durante a maior parte do período analisado, de 4 páginas, sendo as duas últimas voltadas principalmente para anúncios comerciais. Os editoriais geralmente eram posicionados na primeira página, muitas vezes no topo. Esse posicionamento dos discursos na publicação demonstra a importância que a opinião dos pensadores locais tinham para os produtores, assinantes e compradores do jornal nesse período.

O objetivo do periódico era promover a sociedade local, divulgando as peculiaridades da cidade, tal como afirma Chaves (2011: 30):

[o objetivo do periódico era divulgar] os acontecimentos políticos; as atrações culturais; a vida social; os avanços urbanos e tecnológicos e os problemas decorrentes de tais avanços; os acontecimentos fortuitos e pitorescos; quem chegava e quem partia; tudo era objeto das colunas publicadas em O Progresso.

Em $1^{\circ}$ de janeiro de 1913 o periódico, agora de propriedade da Companhia Tipográfica Pontagrossense, se torna finalmente um diário, passando a se chamar Diário dos Campos, o que demonstra a aceitação da publicação por parte dos leitores.

A publicação acompanhava, refletia, questionava e debatia sobre os mais variados acontecimentos aos quais a sociedade pontagrossense entrava em contato naquele período. Tendo surgido em uma época de industrialização da cidade, o periódico foi conquistando espaço no público dos Campos Gerais na medida em que a cidade foi aumentando sua influência na região (REIS, 8 Out. 1915: 1) e se tornou o jor- 
nal de maior circulação na região. Numa época em que alguns grupos sociais se apropriavam dos ideais progressistas, o periódico também surgiu, nas palavras de seu fundador, "pequerrucho", mas com "o progresso" até no título. Tal como afirma Holzmann (27 abr. 1915: 1) na edição comemorativa dos oito anos do periódico:

Faz hoje oito annos que veio à luz um "pequerrucho", conforme mostra o retrato da nossa primeira página, o qual era para receber o nome de "O Pontagrossense", mas, devido ao seu raquitismo, não pode comportar este extenso nome, e foi então que o batizaram de "O Progresso", cujo nome antigo e batido veio a calhar, porque não só ele progrediu, como toda a cidade o acompanhou na mesma vereda.

Durante o período de publicação, personagens eminentes como Belisário Pena, Rui Barbosa e Olavo Bilac foram reproduzidas no periódico, além de entrevistas concedidas ou discursos públicos reproduzidos na publicação.

Nas publicações do periódico é constante a preocupação de buscar - ao mesmo tempo em que se associava com os discursos científicos da época - falar na linguagem popular para atingir um maior número da população letrada ponta-grossense.

Contudo, desde a sua fundação, o jornal enfrentou constantemente as dificuldades financeiras, passando pelas mãos de diversos proprietários, nos seus primeiros anos, dando origem a discussões, inclusive, sobre a sua continuidade ininterrupta, em virtude das constantes trocas de chefia. Porém, considera-se que a presença de Jacob Holz- 
mann e Hugo dos Reis nos primeiros anos, e a preocupação do jornal de após 1912, mesmo com a mudança de nome para Diário dos Campos, em ostentar o sub-título de Ex-O Progresso - que se manteve até a saída de Hugo dos Reis - asseguram a publicação manteve uma continuidade ininterrupta.

O jornal, mesmo nos seus primeiros anos, já enfrentava diversas dificuldades para sua manutenção, pois faltava o apoio de patrocinadores e anunciantes, além de ter escassos investimentos, inadimplência dos assinantes e falta de colaboradores qualificados. Nesse aspecto, a entrada de Hugo dos Reis em meio à equipe improvisada que dava vida ao periódico é um fato fortuíto, pois Reis era o primeiro jornalista de profisão que iria atuar no jornal.

Em Ponta Grossa, Hugo dos Reis se tornou um dos ícones do jornalismo. Tendo nascido em Valença, Estado do Rio de Janeiro, em 10 de dezembro de 1884, e migrado para Ponta Grossa, em 1908, com 23 anos completados, sua vinda se deu por recomendação médica para cuidar de um problema de saúde. Após ter chegado à cidade, desde logo buscou atuar no jornalismo local, indo visitar a redação do recémfundado O Progresso. Epaminondas Holzmann (2004: 269), filho do fundador do periódico ponta-grossense, rememoriza sobre o primeiro contato de Hugo dos Reis com o jornal ponta-grossense:

[...] se apresentou, na gerência do jornal, um moço cujo traje logo chamou a atenção: fraque bastante rostido e reluzente, gravata tipo borboleta, chapéu--coco a cobrir uma basta cabeleira en- 
caracolada. Esquálido, com a dentadura saliente e enormes bigodes lusitanos, mais se assemelhava a um agente de empresa funerária, ou então a um poeta trágico, pronto para puxar do bolso tiras e tiras de papel carcomido, com versos e mais versos procura de editor.

Reis, que também era poeta, foi aceito e começou a atuar como redator literário, tornando-se pouco tempo depois, o redator do periódico, onde no período entre 1908 e 1921, galgou as funções desde a redação, até a direção, e após 1915, tornou-se proprietário da publicação, onde se manteve até 31 de agosto de 1921.

Durante sua participação, o jornalista acompanhou os desafios e as mudanças na sociedade e buscou refletir nas páginas da publicação, envolvendo-se constantemente em debates políticos e sociais da Ponta Grossa de sua época, tendo particicipado de diversas campanhas, como pela fundação de uma agremiação de luta pelos direitos dos trabalhadores, pela promulgação do espiritismo, pelo povoamento do interior, e pelo reflorestamento da região, que já era alvo das indústrias madeireiras.

Numa Ponta Grossa que até 30 anos antes fora típicamente escravagista $^{6}$, que mesmo após ser sancionada a lei da abolição de 1888 ,

\footnotetext{
${ }^{6}$ De acordo com o historiador Magnus de Mello Pereira, que elaborou uma tabela sobre a situação da sociedade paranaense com base no relatório do governador Zacarias de Góes e Vasconcelos, Ponta Grossa possuía por volta de 1850, uma populaçãode 3.033 habitantes, dos quais 1.889 eram considerados brancos e outros 1.144 eram compostos por pessoas considerados pardos ou pretos. Das pessoas consideradas não brancas, 1.059 eram escravos, o que sig-
} 
não havia superado, o regime social e cultural de discriminação racial que existia durante a escravidão, e onde a presença constante de discursos sobre a raça apontam para a existência de racismo mesmo após a libertação dos escravos, também Hugo dos Reis, foi alvo de atitudes racistas por parte dos colaboradores do jornal ponta-grossense Diário do Paraná, tendo a publicação rival afirmado que Reis era negro de "más acções", o que, numa época em que a associação entre raça e qualidade morais era comum ${ }^{7}$, equivalia a afirmar que o redator do Diário dos Campos era dotado de defeitos morais e racialmente inferior. A defesa de Reis no editorial intitulado "Uma resposta", apresenta, contudo, uma visão de raça diferente do discurso comum na sociedade pontagrossense daquele período, pois o jornalista afirma que suas ações, e não a sua cor, é que definiam a sua personalidade. Defendendo-se das acusações do redator do Diário do Paraná Reis afirma que:

O negro que mereceu atenção do redactor do "Diário" sou eu [...] nunca fui nem serei desordeiro [...] quanto à ser negro, louvo ao céu por ter-me feito assim, porque poderia ter-me feito

nifica que, 92,57\% da população não-branca de Ponta Grossa era escrava. (PEREIRA, 1996: 53-54).

${ }^{7}$ A ascensão da eugenia provocou mudanças significativas na forma que a sociedade do final do século XIX e início do século XX interpretava o mundo, havendo neste momento, um discurso que legitimava e ao mesmo tempo exigia ações dos cientistas com o intuito de provocar modificações na sociedade. A raça se tornou um fator determinante para a evolução da sociedade e o aprimoramento racial era percebido como a melhor possibilidade de promover o crescimento de uma nação (SILVEIRA, 2005: 32). 
branco, mas branco de acções negras como essas que acaba de practicar o redactor do "Diário" [...] A raça preta de Ponta Grossa, penso eu, sente-se muito feliz com o despreso dos homens do "Diário", cuja affeicção elles dispensam ou devem dispensar". (REIS, 27 jul. 1909: 2).

Em outro caso, Hugo dos Reis, foi agredido com uma violenta pancada na cabeça, em 28 de maio de 1.909, correndo o risco de ser linchado por um grupo de seus rivais. $\mathrm{O}$ fato foi inclusive noticiado no jornal paulista, O Estado de São Paulo, na edição de 29 de maio de 1909. De acordo com a publicação do jornal paulista, reproduzida no Diário dos Campos, em 8 de junho do mesmo ano, o jornalista foi atacado pelo "Sr. Generoso Borges, redactor do Diário do Paraná" quando saía da redação do Diário dos Campos. Hugo dos Reis teria sido agredido em virtude de seu constante posicionamento sobre questões políticas da sociedade local. Assim como o periódico paulista, nos dias seguintes, dezenas de publicações de colaboradores lamentam o fato, e questionam a atitude tomada pelo redator do Diário do Paraná, que feria os direitos de livre expressão, algo defendido por Reis e pela imprensa (DIÁRIO DOS CAMPOS, 8 jun. 1909: 1).

Também o fato de ser um emigrado do Rio de Janeiro lhe rendeu dissabores. Num período de ascensão dos discursos regionalistas, e em especial do paranismo ${ }^{8}$, Reis também foi acusado de ser um estran-

\footnotetext{
${ }^{8} \mathrm{O}$ paranismo foi um movimento regionalista, surgido a partir dos meios intelectais paranaenses, foi definido em 1927, por Romário Martins, para nomear aqueles que possuíam um "amor pelo Paraná" e lutavam pela "glorificação" do
} 
geiro no solo paranense, e de não ser propriamente um paranaense. Reis defendeu-se em um editorial em 1915, afirmando a honestidade de sua gratidão em relação ao Paraná:

É preciso também, que de uma vez por todas, que se fique sabendo que o Paraná é meu, é o meu Estado. Aqui eu renasci de moléstia incurável que, maravilhosamente, se curou...o ser tellurico da terra passou para o meu organismo e talvez eu não precise, como o kaiser, derramar algumas gotas de sangue fluminense para ficar inteiramente paranaense. O poucochito que por ahi pelas pedras das calçadas ficou derramado, em guerra aberta e acesa, o foi pela questão dos limites. E, talvez,não precise reviver a scena kaiseriana pois segundo uns, o cerebro se renova inteiramente a cada 7 anos - o tempo exacto que eu cá estou; sendo, como o corpo, o meu pensamento, paranaense (REIS, $18 \mathrm{fev}$. 1915: 1).

Da mesma forma que Euclides da Cunha acompanhou a quarta expedição contra Canudos, Hugo dos Reis visitou as áreas de confronto durante a Guerra do Contestado, na fronteira entre os Estados do Paraná e Santa Catarina, observando a atuação do exército na região e notando a pobreza e as más condições sanitárias e sociais da população, abandonada pelo poder central.

Durante a sua estadia no periódico, Hugo dos Reis também promoveu diversos concursos culturais com o objetivo de estimular o

Estado. Contudo, os inícios do movimento surgem logo após a emancipação política do Estado em 1853, e durante a disputa entre o Paraná e Santa Catarina pela região do Contestado,os animos paranistas são exacerbados (BATISTELLA, 2012: 1) 
aumento de colaboradores e permitiu a existência de uma diversidade de discursos que permitem a presença de uma multiplicidade de representações sobre os mais diversos aspectos da sociedade local. Manteve também a presença de diversos colaboradores, sendo que a maioria deles eram pertencentes à crescente burguesia urbana de Ponta Grossa. Os colaboradores, pertenciam a uma classe letrada, progressista e adepta dos ideais modernizadores da sociedade paranaense, e compunham o que se compreende como os "intelectuais locais", que, de acordo com os historiadores Chaves e Karvat (2013: 2), era constituído por:

notadamente escritores, que se pautando em diferentes leituras, autores e referências, participaram ativamente das discussões locais. Cabe ressaltar que essas discussões, quando problematizadas, deixam entrever questões de ordem mais ampla, referentes à aspectos nacionais - de foro social, econômico elou político elou, mesmo, internacional, principalmente naquilo que toca os grandes dilemas históricos do século passado, sejam os grandes conflitos bélicos elou a implantaçãode diferentes regimes políticos. Perceba-se que, com isto, o local (ou sua noção)é, aqui, tomado a partir de um jogo de escala, e não mais a partir de, apenas, elementos menores elou curiosos. Com essas possibilidades, ou a partir delas, se abrem novas e amplas possibilidades de problematização e investigação.

Alguns dos principais colaboradores do jornal, como Julio Xavier e Flávio Carvalho Guimarães eram advogados. Alcídio Ribeiro era professor e Francisco Barbosa Maciel que afirmava ter experiência na Real Universidade de Berlim era médico. Atuava em Ponta Grossa rea- 
lizando consultas nas farmácias Minerva, e atendia em outros horários na sua residência.

Epaminondas Holzmann, filho de Jacob Holzmann, fundador do Diário dos Campos, aponta ironicamente no livro "Cinco histórias Convergentes", a liberalidade de Hugo dos Reis, pois segundo o autor, Reis "tolerava todos os poetas de água doce que apareciam na redação, dando-se mesmo ao afanoso trabalho de refazer os escritos de certos colaboradores" (HOLZMANN, 2004: 30).

A atitude amistosa do redator em relação aos colaboradores se demonstrava como na atitude tolerante no caso dos artigos sobre a germanização do sul do Brasil de F. Barbosa Maciel, em que Hugo dos Reis se limita a publicar logo embaixo da ultima parte do artigo uma nota em que afirma em nome do jornal que "não precisamos declarar que sob muitos pontos de vista (...) nossa redação se acha em completo antagonismo com este artigo de fundo" (DIÁRIO DOS CAMPOS, 27 dez. 1915: 1).

Hugo dos Reis, enquanto esteve à frente da publicação, permitiu a existência de uma diversidade de discursos em relação às questões sociais e raciais brasileiras, inclusive permitindo a publicação de pensamentos opostos às suas convicções, como nos casos em que colaboradores do jornal publicam artigos defendendo práticas de eugenia restritiva como a restrição racial e matrimonial. Foi graças à sua liberalidade que é possível a presença de uma diversidade de discursos e representações sobre a sociedade ponta-grossense naquele período, tornando os 
anos de 1908 até 1921, um período rico em produções e diversidade de representações sobre a sociedade no jornalismo ponta-grossense.

\section{Considerações Finais}

Os discursos produzido por Hugo dos Reis, são representações da realidade, ressignificadas a partir da visão do jornalista. Nesse aspecto, concordamos com Chartier, quando este defende que os significados das representações são socialmente construídos e aponta para a necessidade de se "identificar o modo como em diferentes lugares e momentos uma determinada realidade social é construída, pensada, dada a ler" (CHARTIER, 1990: 16).

No momento em que o jornalista se estabelece em Ponta Grossa, a sociedade local passava por ser um período de constantes mudanças, com a abolição da escravidão, a chegada dos imigrantes, o aumento populacional e urbanização, diversificação da economia, surgimento de novas profissões, ascensão de novos discursos científicos e sociais, entre outros. E nessa cidade em burburinho com as novas descobertas, que Hugo dos Reis vem morar, sendo também ele um indivíduo representante das novas classes, por ser um membro da recém surgida imprensa ponta-grossense.

Ao mesmo tempo, compreende-se que as representações que Hugo dos Reis constrói no Diário dos Campos possuem uma íntima relação com os interesses do grupo social ao qual ele faz parte. Os dis- 
cursos do jornalista buscam apoiar o surgimento da classe jornalista no meio local, e as representações que produz, atendem aos interesses dessa classe. Sobre a importância dos interesses do grupo na construção das representações, Chartier, afirma que "As representações do mundo social assim construídas, embora aspirem a universalidade de um diagnóstico fundado na razão, são sempre determinadas pelos interesses de grupo que as forjam" (CHARTIER, 1990: 17).

O estudo é concluído no momento em que Hugo dos Reis deixa a publicação, em 31 de agosto de 1921. A partir desse momento, o jornal passa para as mãos de outros responsáveis, primeiramente o advogado Dr. Toscano de Brito e depois José Cadilhe. Após essa data, Hugo dos Reis continua por alguns anos como uma figura eminente da sociedade ponta-grossense. Contudo, na metade da década de 1920, ele se muda para o interior de São Paulo. A maioria dos outros colaboradores ainda é citada e alguns publicam alguns artigos pelo periódico, como Flávio C. Guimarães, que continuou atuando na cidade como advogado. Todavia, a sua presença é mais esparsa. Enquanto isso, outros pensadores mais polêmicos como F. Barbosa Maciel e Martins Pinto, desaparecem das páginas do jornal.

No momento pós-Hugo dos Reis, o jornal perde parte da combatividade dos discursos. Não encontram-se mais os debates acirrados que envolveram dezenas de edições e que apresentaram uma diversidade de representações como aquele envolvendo o médico F. Barbosa Maciel e colaboradores do jornal, como Flavio C. Guimarães e Junqueira e Guer- 
ra entre os anos de 1915 e 1916 (HOLOWATE, 2015). O jornal se torna mais de pensamento unilateral, e menos aberto às discussões que tanto caracterizaram a publicação enquanto esteve sob a égide do jornalista Hugo dos Reis.

\section{FONTES CITADAS}

Diário dos Campos. 15 Annos passados. Ponta Grossa, 27 abr. 1922, p. 1. . Ponta Grossa. 27 de dezembro de 1915, p.1.

HOLZMANN, Jacob. 8 Annos. Diário dos Campos. Ponta Grossa, 27 abr. 1915, p. 1.

O caso de Ponta Grossa. Diário dos Campos. Ponta Grossa, 8 Jun. 1909, p. 1 .

REIS, Hugo dos. Ponta Grossa no Estado. Diário dos Campos. Ponta Grossa, 8 de outubro de 1915, p. 1.

. Deixando a chefia. Diário dos Campos. Ponta Grossa, 18 fev. 1915, p. 1. . Instituto disciplinar. Diário dos campos. 27 mar. 1918, p. 1.

. O grupo escolar de Palmas. Diário dos Campos. Ponta Grossa, 9 out. 1915 , p. 1.

. Uma resposta. O Progresso. Ponta Grossa, 27 jul. 1909, p. 2.

\section{REFERÊNCIAS}


BATISTELLA, Alessandro. O paranismo e a invenção da identidade paranaense. Revista Eletrônica História em Reflexão: Vol. 6 n. 11. Dourados, UFGD; jan/jun 2012.

CHARTIER, Roger. A História Cultural: Entre Práticas e Representações. Lisboa: Ed. Difel, 1990.

. O mundo como representação. Estudos Avançados, vol.5, nº.11, jan/abr. 1991, p. 173-191.

CHAVES, Niltonci Batista; KARVAT, Erivan Cassiano. Intelectuais, Discursos e Instituições: as relações entre a História Intelectual (e/ou de Intelectuais) e a História Local (reflexões sobre possibilidades de pesquisa). Anais do VI Congresso Internacional de História. Maringá: UEM, 2013.

CHAVES, Niltonci Batista. Entre "preceitos" e "conselhos": Discursos e práticas de médicos-educadores em Ponta Grossa/PR (1931-1953). Curitiba, Tese de Doutorado, Universidade Federal do Paraná, 2011.

HOLOWATE, Isaias. F. Barbosa Maciel versus Flávio C. Guimarães: Debates eugenistas em Ponta Grossa. Anais da X Semana de História. Irati: UNICENTRO, 2015.

. Relações de poder: A contenda entre o Jornal Diário dos Campos e a Câmara Municipal no alvorecer da imprensa ponta-grossense. Revista Mídia \& Contexto, v. 02, nº4, p. 1-17; ago-set. 2015.

HOLZMANN, Epaminondas. Cinco Histórias Convergentes. Ponta Grossa: UEPG, 2004.

KOHLRAUSCH. Arlindo Jonas Fagundes. Introdução à história da arquitetura em Ponta Grossa/Pr: As casas de madeira - 1920 a 1950. Dissertação de Mestrado. São Paulo, USP; 2007, p. 20. 
LEANDRO. José Augusto. Palco e tela na modernização de Castro. Dissertação de Mestrado. Curitiba, UFPR; 1995.

LE GOFF, Jacques; NORA, Pierre. História: Novos problemas. 1. ed. Rio De Janeiro: Francisco Alves, 1978.

LUCA, Tania Regina de. História dos, nos e por meio dos periódicos. In: PINSKY, Carla Bassanezi, (org). Fontes Históricas. $3^{\circ}$ ed. São Paulo, Contexto, 2011.

MALDONADO, Elaine Cristina. Machado de Assis e o espiritismo: diálogos machadianos com a doutrina de Allan Kardec (1865-1896). Dissertação de Mestrado. Assis, UNESP, 2008, p. 11.

PEREIRA, Magnus Roberto de Mello. Semeando iras rumo ao progresso. Curitiba, UFPR, 1996.

PINTO, Elisabete Alves. A população de Ponta Grossa a partir do registro civil. - 1889- 1920. Dissertação de Mestrado. Curitiba, UFPR, 1980.

PONTES, Felipe Simão; SILVA, Gislene. Mídia noticiosa como material de pesquisa: Recursos para a pesquisa de produtos jornalísticos. In: BOURGUIGNON, Jussara Ayres; OLIVEIRA JUNIOR, Constantino Ribeiro de, (orgs). Pesquisa em Ciências sociais: interfaces, debates e metodologias. Ponta Grossa. Toda palavra, 2012.

SILVA, Natalia Ferronatto Da,. As "Virgens Messianicas": A Participação e influência das virgens Teodora e Maria Rosa no Contestado 1912-1916. Disponível em: http://seer.cfh.ufsc.br/index.php/sceh/article/download/331/168 
Cadernos de Clio, Curitiba, v. 7, nº 1, 2016

SILVEIRA, Éder. A cura da raça: eugenia e higienismo no discurso médico sul-riograndense nas primeiras décadas do século XX. Passo Fundo: Editora Universitária de Passo Fundo; 2005.

ZULIAN, R.W. A victoriosa rainha dos campos: Ponta Grossa na conjuntura republicana. Revista de História Regional; 3(2):37-76, 1998.

Recebido em: 15/03/2016 Aceito em: 03/08/2016 
